\title{
An Integrated Model for Simulating Regional Water Resources Based on Total Evapotranspiration Control Approach
}

\author{
Jianhua Wang, Xuefeng Sang, Zhengli Zhai, Yang Liu, and Zuhao Zhou \\ State Key Laboratory of Simulation and Regulation of Water Cycle in River Basin, \\ China Institute of Water Resources and Hydropower Research, 100038, China \\ Correspondence should be addressed to Xuefeng Sang; xuefengsang@gmail.com
}

Received 29 January 2014; Revised 3 June 2014; Accepted 24 June 2014; Published 14 July 2014

Academic Editor: Dawei Han

Copyright (C) 2014 Jianhua Wang et al. This is an open access article distributed under the Creative Commons Attribution License, which permits unrestricted use, distribution, and reproduction in any medium, provided the original work is properly cited.

Total evapotranspiration and water consumption (ET) control is considered an efficient method for water management. In this study, we developed a water allocation and simulation (WAS) model, which can simulate the water cycle and output different ET values for natural and artificial water use, such as crop evapotranspiration, grass evapotranspiration, forest evapotranspiration, living water consumption, and industry water consumption. In the calibration and validation periods, a "piece-by-piece" approach was used to evaluate the model from runoff to ET data, including the remote sensing ET data and regional measured ET data, which differ from the data from the traditional hydrology method. We applied the model to Tianjin City, China. The Nash-Sutcliffe efficiency (Ens) of the runoff simulation was 0.82, and its regression coefficient $R^{2}$ was 0.92 . The Nash-Sutcliffe Efficiency (Ens) of regional total ET simulation was 0.93 , and its regression coefficient $R^{2}$ was 0.98 . These results demonstrate that ET of irrigation lands is the dominant part, which accounts for $53 \%$ of the total ET. The latter is also a priority in ET control for water management.

\section{Introduction}

Water resources are becoming increasingly interconnected with social, economic, environmental, and political issues at national, regional, and even international levels [1]. A hydrological cycle study usually takes into account precipitation, surface runoff, rivers, and groundwater, but it should now also incorporate four components of the human water cycle: uptake of water, transportation of water, use of water, and drainage and regress. Thus, recent hydrological cycles have the characteristics of both a natural process and a human intervention [2].

In general, hydrological models can be classified into lumped models and distributed models, which are also called data-driven models and mechanistic models [3]. Lumped models, such as linear time series models, nonlinear time series analysis [4-6], and regression models [7], can be used for various purposes, such as forecasting and modelling rainfall runoff and estimation of missing hydrological data. In past decades, distributed hydrological models, for example, the SWAT model [8], TOPMODEL [9], MODFLOW [10], FEFLOW [11], MIKE-SHE model [12], SVM model [13],
HSPF model [14], and VIC model [15], have been developed and widely used for water planning and management.

Nonetheless, a pragmatic model should include not only natural factors such as plants, soil, and climate but also water use in society and in the economy [16]. The abovementioned specialized hydrological models used for water management have limitations in regions affected by human activities. It is known that the remote sensing (RS) technique can objectively quantify different types of evapotranspiration (ET) as a function of time [17]. In this work, we developed the water allocation and simulation (WAS) model to simulate different types of natural ET and various types of artificial water consumption; a "piece-by-piece" approach was utilised to evaluate the model from runoff to ET.

\section{The WAS Model}

The WAS model can simulate dually natural-artificial water cycles influenced by both nature and humans. It consists of two interoperative computational modules: SWAT and the artificial water optimized allocation module (AWOM), which was developed in this study. In particular, AWOM, which 
TABLE 1: Generalized elements of the system of water resources in AWOM.

\begin{tabular}{lcc}
\hline Elements & Class & The representative system \\
\hline \multirow{2}{*}{ Points } & Supply & Reservoir, diversion works, well project, lakes, and marshes \\
& Water use & City residents, rural residents, industry, agriculture, urban ecology, lake ecology, and wetland ecology \\
& Convergence & Catchment zones and outflow, such as an ocean or a lake \\
& Water control & Key section of a river or channel \\
\hline \multirow{2}{*}{ Lines } & River & Natural rivers \\
& Channel & Artificial channels \\
\hline
\end{tabular}

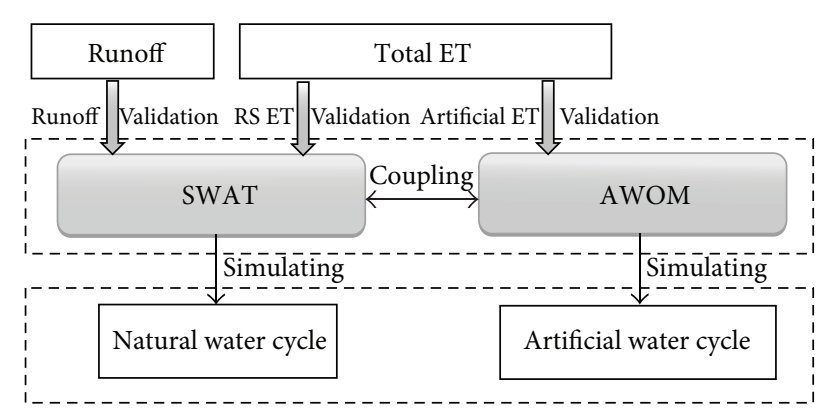

FIGURE 1: The structure of the WAS model (RS ET is ET data retrieval with remote sensing).

can implement optimization of regional water utilization by regional ET control, is the core for regional water resource management. SWAT provides basal data to AWOM. Synchronously, the SWAT and AWOM are the key to ET control of a region because regional ET includes not only natural ET such as ET of soil, grass, crops, and water (which can be obtained from SWAT and verified with data from RS) but also artificial ET-like consumptive use (ET) by residential buildings and by the industry, which can be provided by AWOM. Total regional ET can be verified using the water balance method and simulated using the WAS model, which is shown in Figure 1. Figure 1 shows the general architecture and state information flows of the WAS model, and Figure 2 illustrates the overall cyclic flow of this model.

2.1. Development of the SWAT Model. SWAT was initially developed by the United States Department of Agriculture for comprehensive modelling of the impact of management practices on water yield, sediment yield, and crop growth in large complex watersheds [8]. There are some disadvantages of SWAT. One example is that its artificial water simulation is limited and the scenarios are set passively; therefore, it cannot actively resolve conflicting water allocation options using data from social, economic, environmental, and water resources. In our study, some functions of SWAT were developed to incorporate the impact of human activities as follows. (1) We improved the agriculture module by adding an irrigation function that can locate more water sources for irrigation water within the same time frame. (2) We developed the consumptive water use module, which may be adapted to spatial and temporal variability of water use in different years; these data have been published previously [18].
2.2. Development of AWOM. Allowing for natural and artificial "dualistic" characteristics of a hydrological cycle, AWOM that is based on the ET control theory has been utilised in this work to simulate the artificial water cycle.

2.2.1. Description of the Water System Methodology. A water system methodology for the regional water resources is used here to describe an actual water system in AWOM, which includes five components (Figure 3): (a) multiple water sources, such as surface water, ground water, transfer water, recycled water, and desalination and brackish water; (b) multiple storage facilities, such as reservoirs, diversion works, well projects, lakes, and marshes; (c) multiple transfer systems, such as natural rivers, artificial channels, and the pipe network; (d) multiple users, including city residents, rural residents, industry, agriculture, ecology, and shipping; and (e) multiple drainage systems, including rivers, rainwater channels, and sewage channels.

2.2.2. Generalized Methodology of the Water System. Because of the complexity of the real-world system of water resources, we need to abstract the main characteristics and processes of a real water resource system according to an actual situation in the region. According to the similarity principle, the regional system of water resources is usually generalized as point elements and line elements to describe generalized water resources (Table 1 ).

2.2.3. The Delineation Method for Subzones. A study area may be divided into water allocation units (WAUs). WAUs are portions of a subbasin that possess unique subwatersheds or attributes of administrative divisions. The delineation process requires a digital map of subwatersheds and a map of administrative divisions in the shape (PolyLine) format. WAUs should be delineated via superimposition of the two above-mentioned maps in ArcGIS software (Figure 4).

\subsubsection{The Relationship between Data from AWOM and SWAT.} The holistic approach can objectively and clearly demonstrate the amount of allocation and drainage of water and show where it comes from and where it goes. In particular, AWOM is suitable for optimisation of the profit from water resources according to water availability per capita and a higher value of use considering regional ET control, groundwater exploitation control, among other factors that can improve development of water resources and of the regional economy. In fact, some input data for AWOM, such as runoff, groundwater, and 


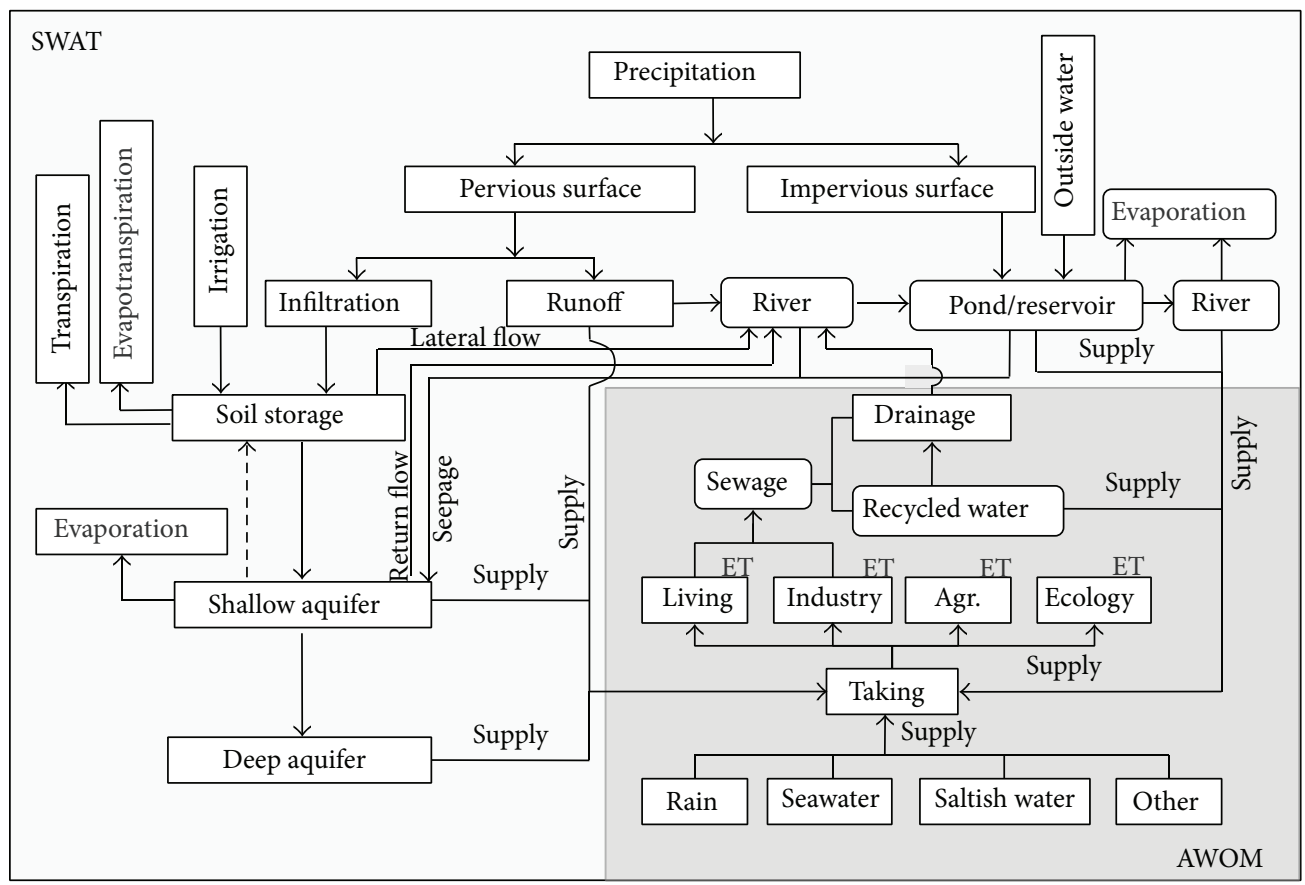

Figure 2: The flow chart of the WAS model.

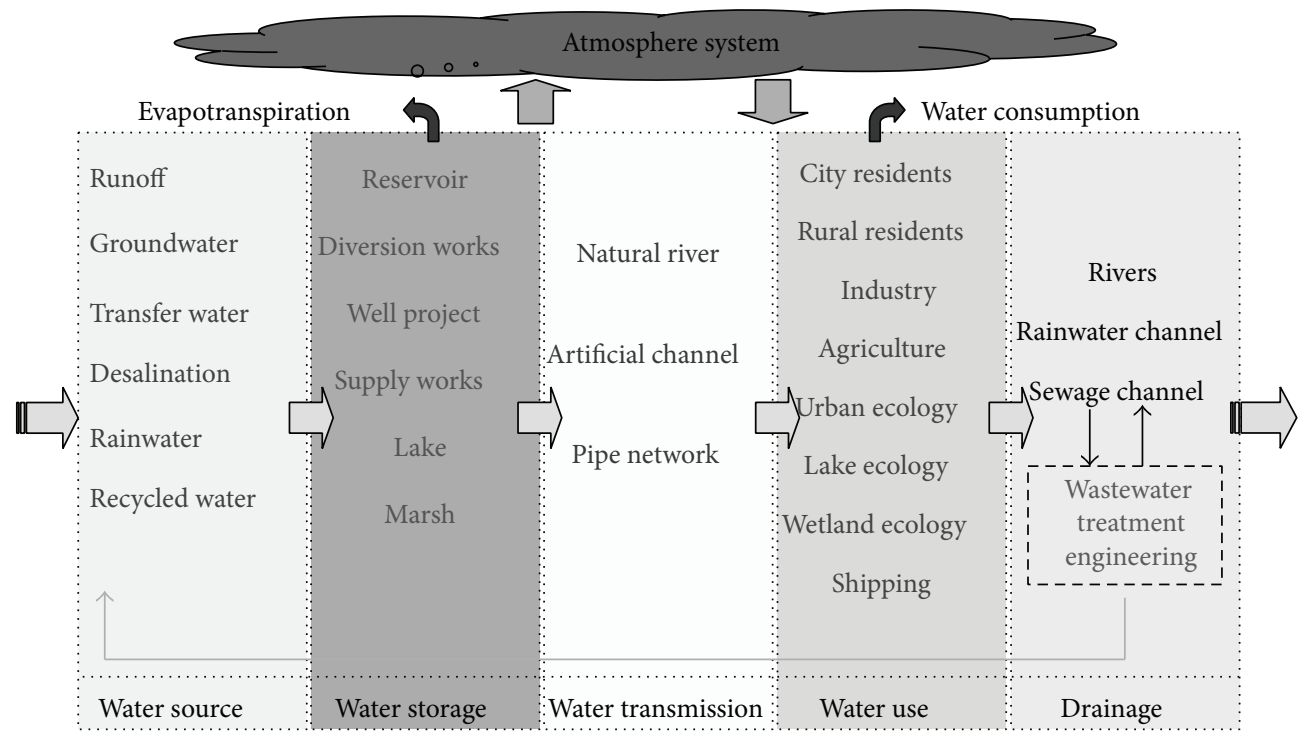

Figure 3: Description of the water system in AWOM.

water of sluice facilities, are as important as the output data on water resources demanded by users. In this study, water source data are provided as output of SWAT. Homoplastically, output variables of AWOM for a study region (which reflect the artificial consumptive water process) can be spatially and temporally assimilated into SWAT and used for calculations.

\section{Practical Application of the Model}

The WAS model described above was applied to Tianjin City, which has an area of $11,920 \mathrm{~km}^{2}$ and had a population of 13.6 million in 2011. Tianjin City is located in the northern part of China and is the last city downstream of the Hai River flowing into the Bo Sea.

\subsection{Materials}

3.1.1. Hydrological Data. The input of the WAS model involves a large amount of data, which include the following: (1) the DEM of Tianjin is SRTM $30 \mathrm{~m}$ digital elevation data (downloaded from http://srtm.csi.cgiar.org/); (2) data on a regional river system on the scale of $1: 250,000$, obtained from the Water Resource Department of Tianjin (Figure 5); 

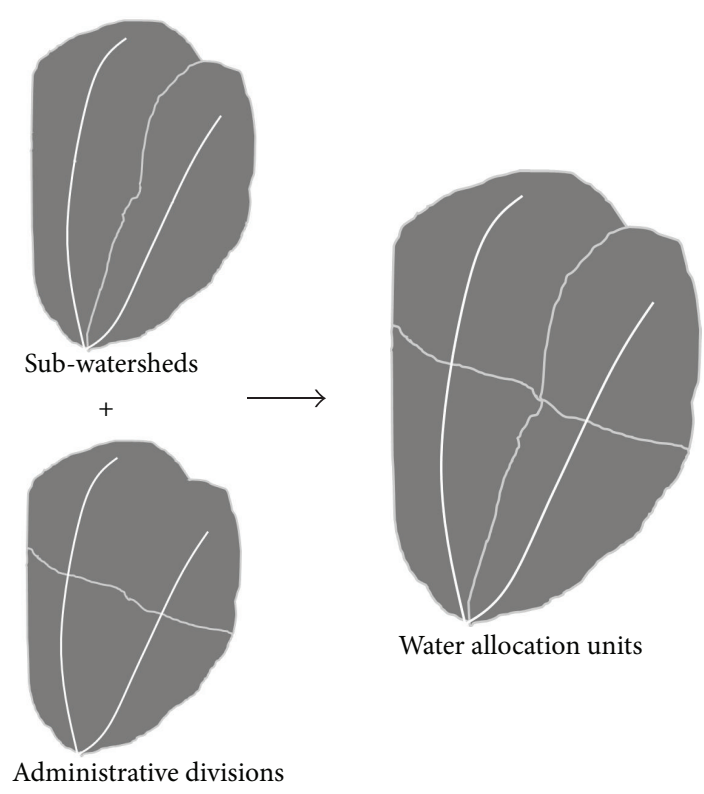

FIgURE 4: Delineation of water allocation units.

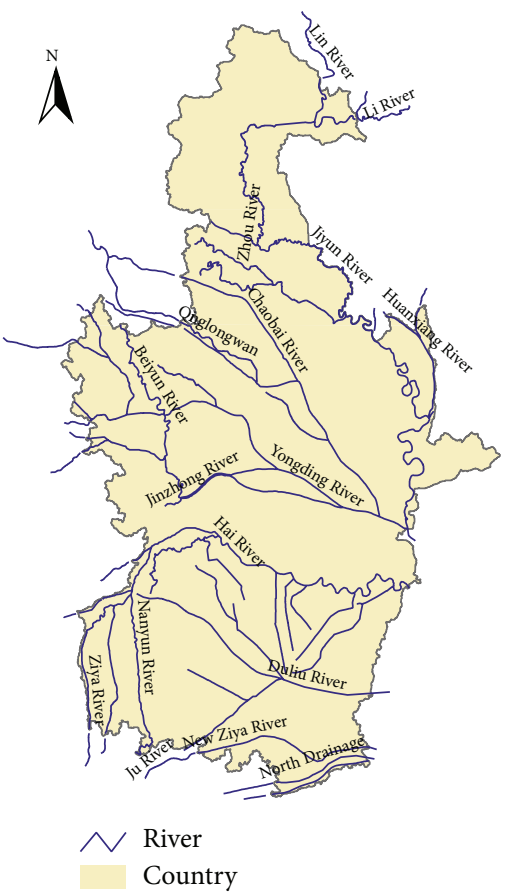

Figure 5: Rivers in Tianjin.

(3) daily weather data, including information on precipitation, temperature, wind speed, solar radiation, and relative humidity, supplied by the National Meteorological Site of China; (4) regional river inflow data obtained from the Water Resource Department of Tianjin; (5) soil types and types of land use (Figures 6 and 7) provided by the Water Resource Department of Tianjin; (6) infiltration recharge data from rainfall, rivers, reservoirs, wetlands, and irrigation and data on geological parameters for the groundwater
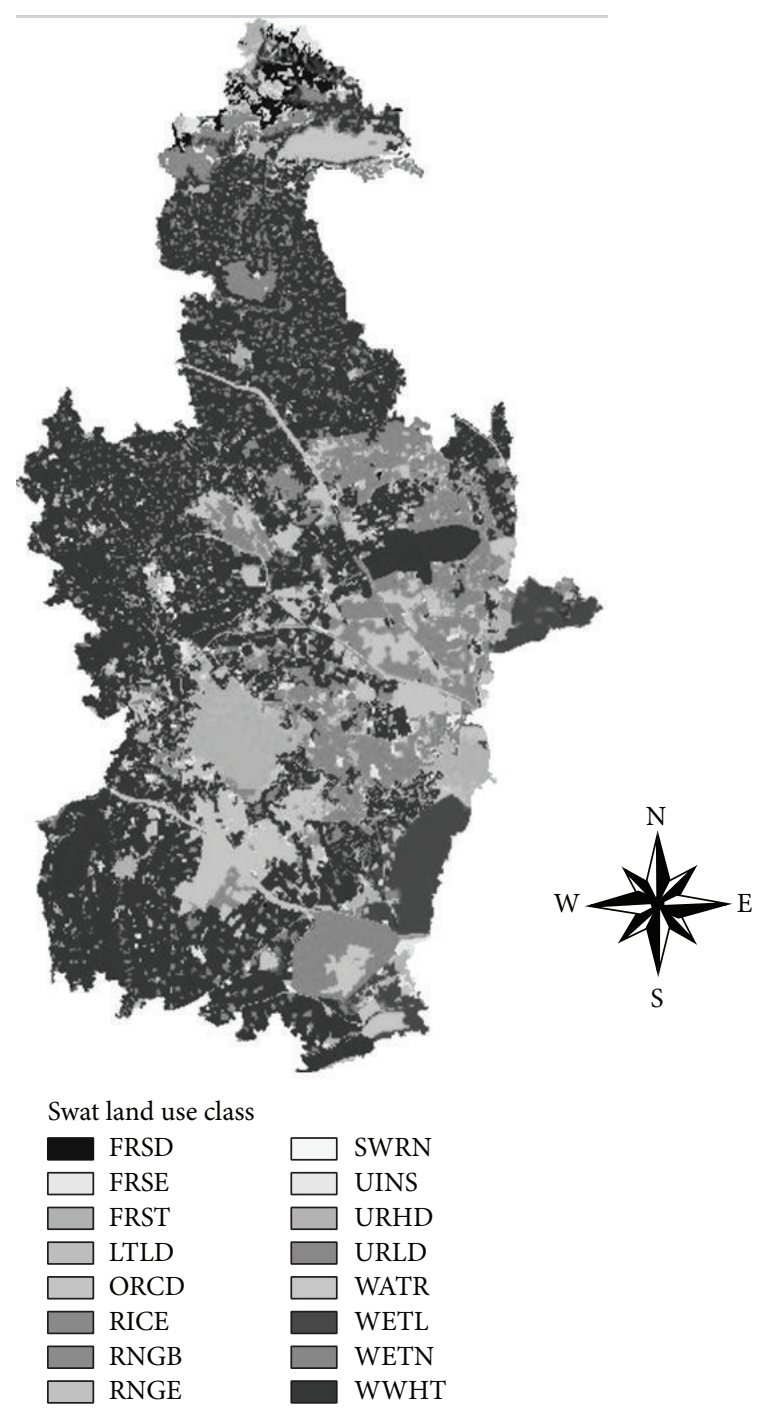

Figure 6: Land use in Tianjin.

aquifer, obtained from the Water Resource Department of Tianjin.

3.1.2. Artificial Data. The artificial data comprises five components: (1) the volume of water demanded by a city and industry; (2) the data on the schedule of irrigation, crop planting, fertilization, and other parameters related to farming management; (3) the volume of waste water drained by the city and industry; (4) the water supply source of each zone; and (5) the relationship of supply and drainage among various supply systems and demand zones. All of the above data were obtained from Tianjin water resource departments.

3.2. Development of the Model. The boundaries of the model follow the borders of the Tianjin district and some natural features, such as rivers, creeks, and coastline. As for the land surface, the research area was divided into 325 subbasins and 1,414 hydrologic response units in the SWAT model based on DEM, soil type, and land use of Tianjin (Figure 8). The water resource system of the Tianjin basin was generalized 
TABLE 2: The delineated subzones of Tianjin in AWOM.

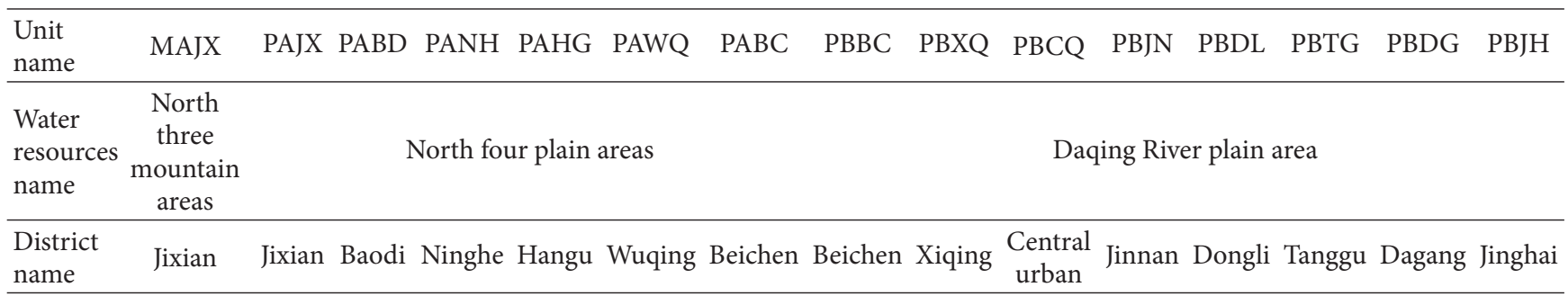

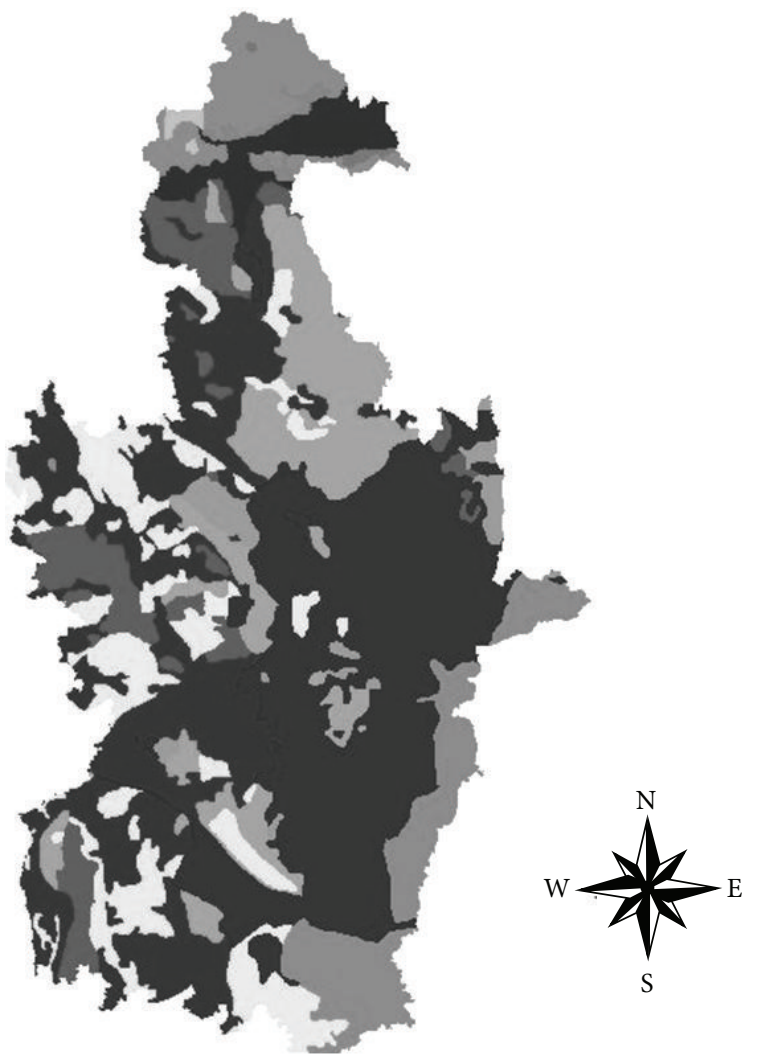

Soil class

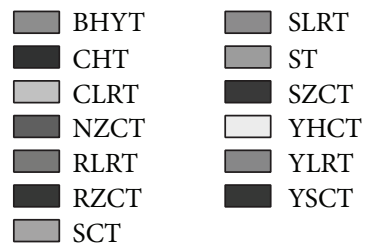

FIgURE 7: Soils in Tianjin.

to describe the four processes of the Tianjin artificial water cycle (Figure 9). The artificial zones were delineated as 15 subzones in AWOM using the method that superimposes the watershed and the district.

The name of a subzone is an abbreviation, composed of four letters; the first two letters represent the regionalisation of water resources and the last two letters represent district regionalization. Table 2 shows descriptions of subzones.

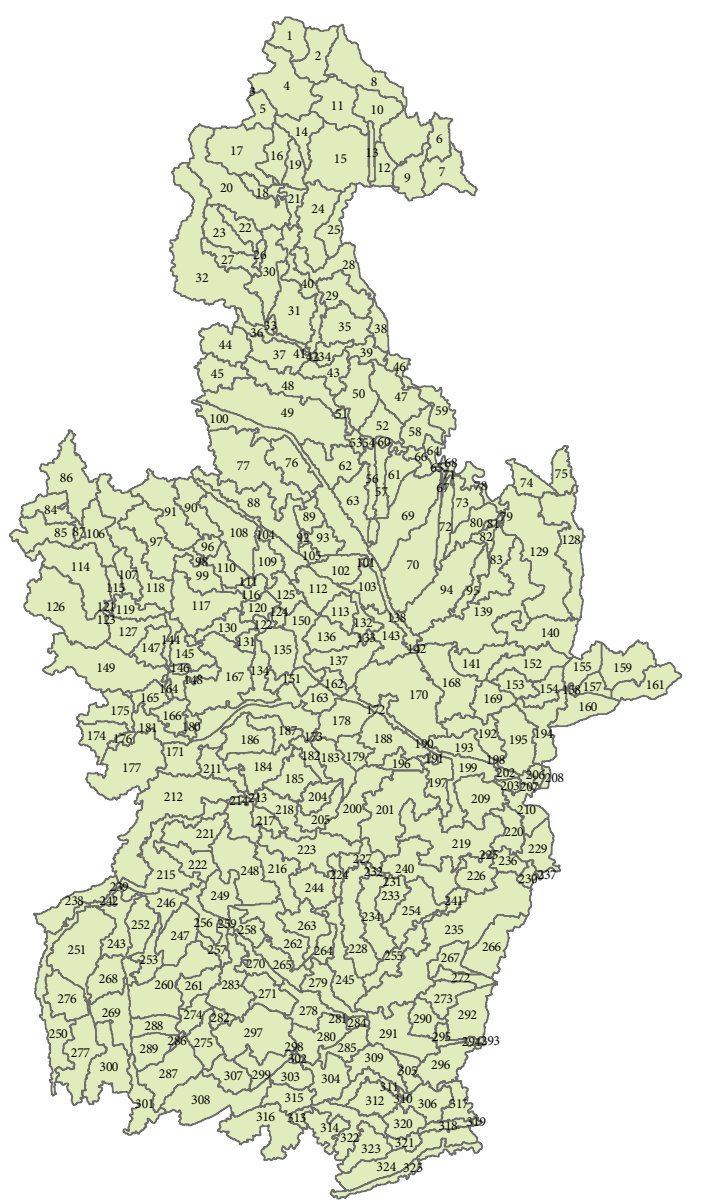

FIGURE 8: Delineation of watersheds in the Tianjin basin.

\section{Results and Discussion}

A "piece-by-piece" approach was used here to evaluate the WAS model from runoff to ET. The idea behind the pieceby-piece approach is to provide the model with rational and available results step by step. The WAS model, like other large models, is subdivided into several pieces and then solved step by step with one piece solved at each step. At each step, the solution of the current partial model begins with a solution found in the previous step, and the solution from the current step is saved for the next step. At the final step, the model contains all pieces and the whole model is then calibrated. Verification of the WAS model is subdivided into 


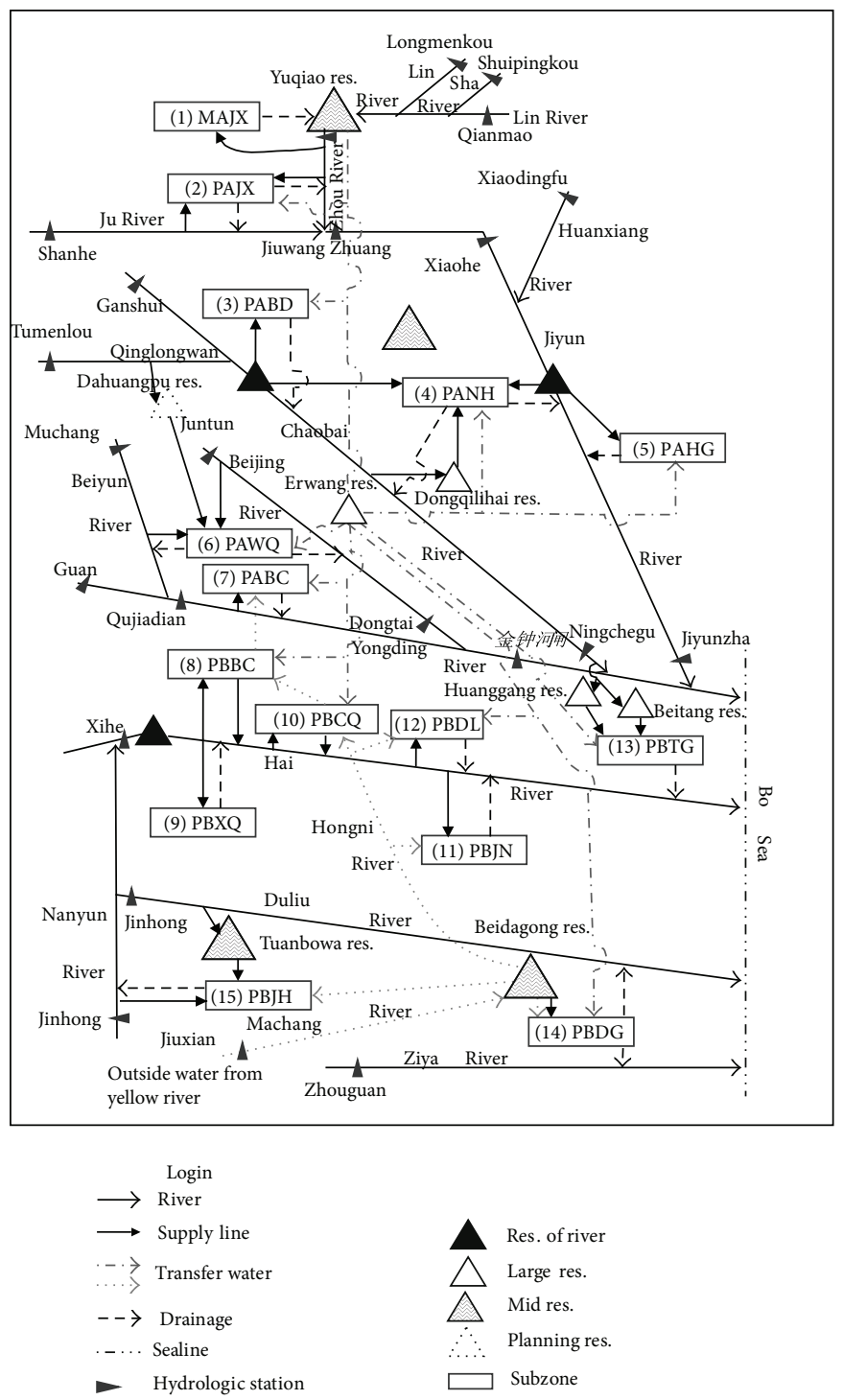

FIgURE 9: Water resource network of Tianjin.

the following three parts: the runoff, the ET measured using water balance analysis, and the ET obtained by means of RS.

4.1. Verification of the Model on Runoff. The surface runoff in the Tianjin basin was calibrated with daily observed streamflow data from 1985 to 1999 from four hydrological stations in Tianjin: on the Jiyun River, on the Chaobai River, on the Hai River, and on the Duliujian River. Comparison of the simulated and observed daily stream flow involved model efficiency (Ens) [19] and a regression coefficient $\left(R^{2}\right)$. Surface runoff was calibrated until average measured and simulated surface runoff had monthly $R^{2}>0.6$ and Ens $>0.5$. The results of the calibration are shown in Figure 10.

The Nash-Sutcliffe efficiency (Ens) of the model was 0.82 on average, with the maximum 0.89 and minimum 0.78 ; its regression coefficient $R^{2}$ was 0.92 on average, with the maximum 0.94 and minimum 0.91 (Table 3 ).

Several factors may contribute to the discrepancies between the simulation and the observed data. (1) The hydrological cycle was strongly affected by human activities, and the spatial-temporal distribution of artificial water use in the model fails to reflect a real situation, although the SWAT module was developed to account for human activities. (2) The schedule of irrigation was also an influential factor because irrigation represented the dominant water use $(70 \%$ of all off-stream uses), and the irrigation data necessitated consideration of precipitation and soil moisture. Overall, the predictions of runoff are relatively acceptable.

4.2. Verification of the Model on ET Measured Using Water Balance. Regional total ET includes natural ET and artificial ET. The ET measured using water balance is calculated from inflow and rainfall data and outflow data in Tianjin from 1980 to 2004; these measurements were made by Tianjin water resource departments (Figure 11).

In this work, ET of various underlying surface features was simulated and analysed using the distributed hydrology 


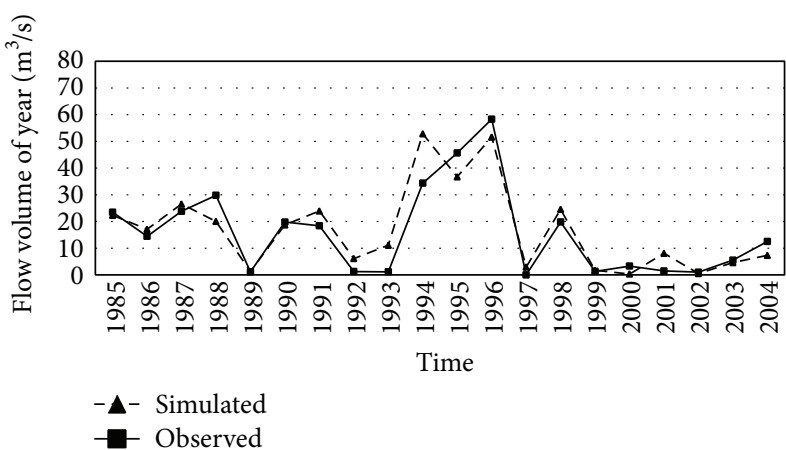

(a)

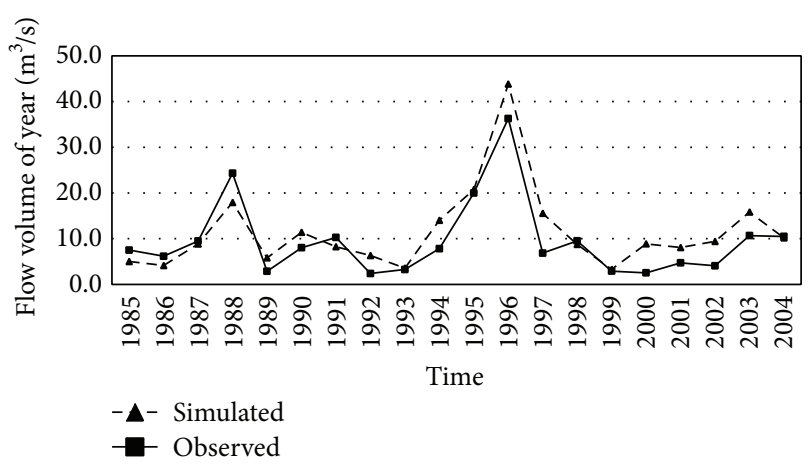

(c)

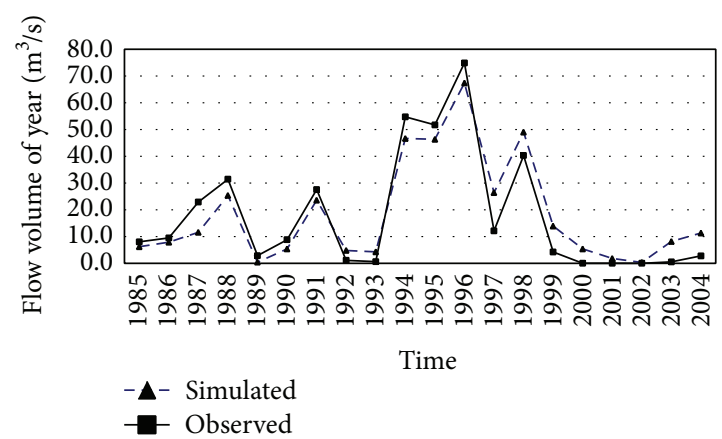

(b)

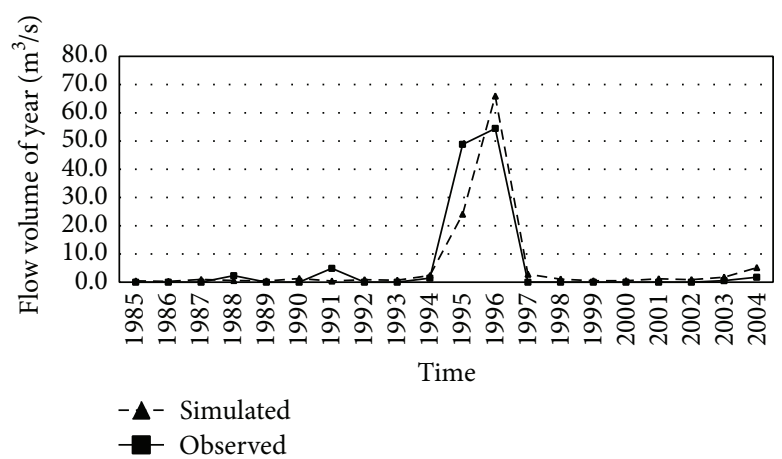

(d)

Figure 10: Calibration of the model. Comparison between simulated and observed streamflow at the four stations: Jiyun River (a), Chaobai River (b), Hai River (c), and Duliu River (d).

TABLE 3: Correlations at the four observed stations during calibration and validation periods.

\begin{tabular}{lcccccccccc}
\hline & \multicolumn{4}{c}{ Calibration period (1985-1999) } & \multicolumn{4}{c}{ Validation period (2000-2004) } \\
ID & $\mathrm{a}$ & $\mathrm{b}$ & $\mathrm{c}$ & $\mathrm{d}$ & Average & $\mathrm{a}$ & $\mathrm{b}$ & $\mathrm{c}$ & $\mathrm{d}$ & Average \\
Station & Jinyun & Chaobai & Hai & Duliu & & Jinyun & Chaobai & Hai & Duliu \\
\hline Nash & 0.82 & 0.89 & 0.78 & 0.82 & 0.82 & 0.61 & 0.78 & 0.65 & 0.73 & 0.69 \\
$R^{2}$ & 0.91 & 0.94 & 0.92 & 0.91 & 0.92 & 0.67 & 0.82 & 0.75 & 0.78 & 0.76 \\
\hline
\end{tabular}

Nash: Nash-Sutcliffe efficiency (Ens); $R^{2}$ : regression coefficient.

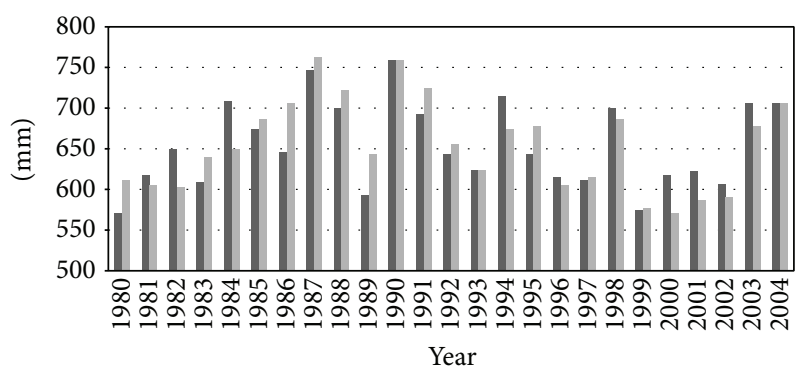

- ET measured by water balance

- ET simulated by WAS

FIGURE 11: Comparison of total ET between simulated and measured data.

model of SWAT, and artificial ET was simulated and calculated in the artificial consumptive water module of AWOM. Figures 5 and 6 show comparisons of integrated regional ET between the simulation and the measured data, which were obtained in the analysis of water balance in Tianjin. The Nash-Sutcliffe efficiency (Ens) of the model was 0.67, and its regression coefficient $R^{2}$ was 0.83 . From 1980 to 2004 (Figure 12 ), $64 \%$ of years deviated by less than $5 \%$ and $88 \%$ of years deviated by less than $8 \%$. The average total ET of 25 years simulated by the WAS model was $654 \mathrm{~mm}$, which equalled the measured ET.

4.3. Verification of the Model on ET Obtained Using RS. Currently, the margin of error of ET obtained using RS can be larger than 15 percentage points, but the relationship of ET with various types of land use is accurate on a spatial scale in the same period. Therefore, we compared the ET results (average value from 2001 to 2004) pertaining to various types of land use between the WAS model and RS in order to validate the results for the model for various types of land use.

We found that the ET simulated by the WAS model was close to the ET data retrieved using the RS technique on different lands, as shown in Figure 13. The Nash-Sutcliffe 


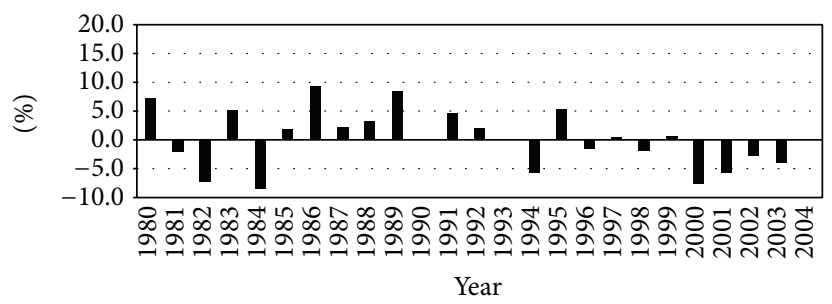

FIGURE 12: The deviation rate of simulated ET compared to measured ET.

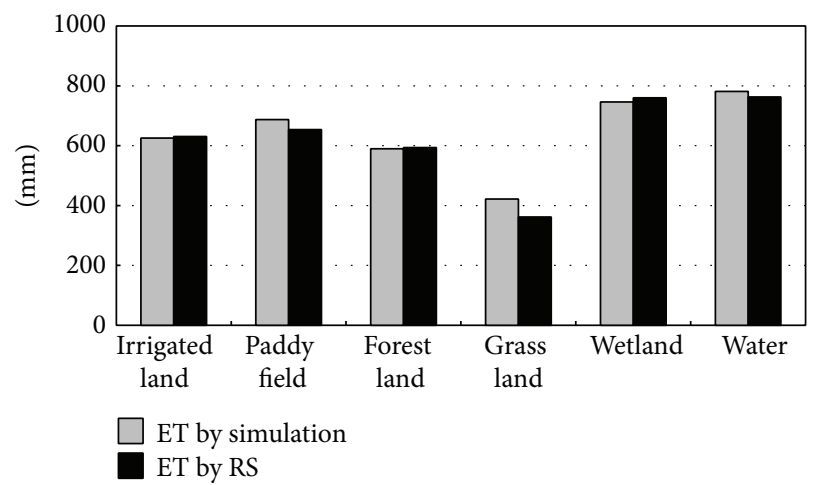

FIGURE 13: Comparison between simulated ET from the model and observed ET from RS in various lands.

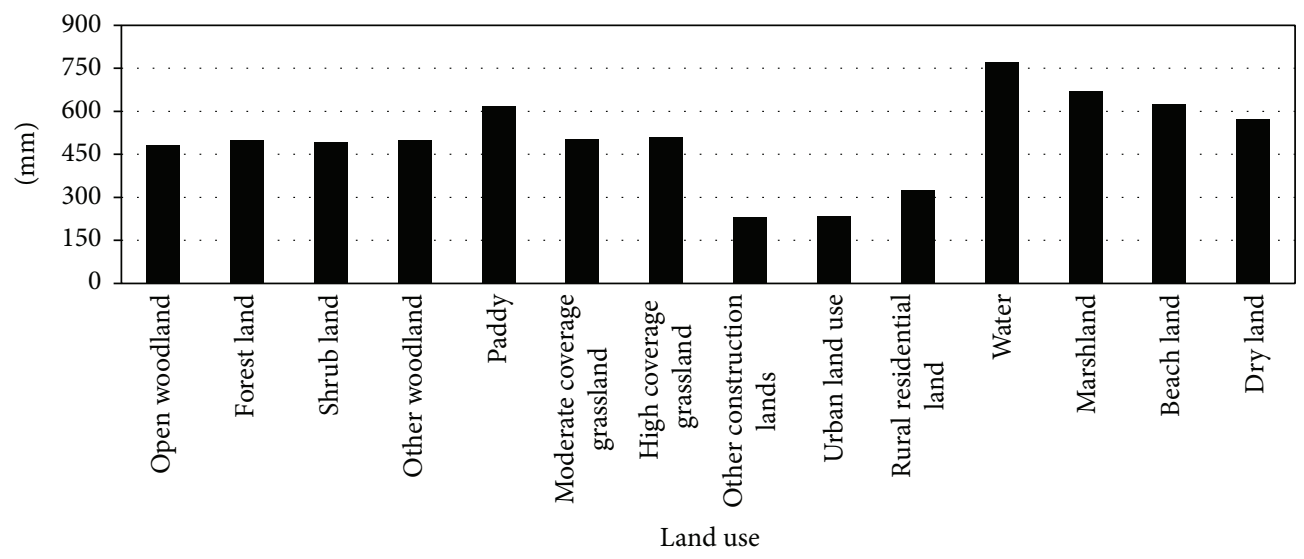

Figure 14: Average ET of lands used for various purposes in Tianjin from 1980 to 2004.

efficiency (Ens) of the model was 0.93, and its regression coefficient $R^{2}$ was 0.98 . The ET from water, wetlands, and paddy lands was higher than that from the irrigated land, forest, and grass land; these results were consistent with the actual context and regional features.

\section{Analysis of Regional Total ET}

The average ET of various types of land use in Tianjin from 1981 to 2004, calculated by the WAS model, is shown in Figure 14. The water ET is $991 \mathrm{~mm}$ on average and was the highest. Marsh land and beach land are the second and the third: $724 \mathrm{~mm}$ and $701 \mathrm{~mm}$, respectively. ET of paddy fields and dry lands is also high, $602 \mathrm{~mm}$ and $530 \mathrm{~mm}$, respectively. Then follow grassland and forest land, from $482 \mathrm{~mm}$ to $501 \mathrm{~mm}$. The rural residential land, urban land, and other construction lands showed low ET: $326 \mathrm{~mm}, 236 \mathrm{~mm}$, and $233 \mathrm{~mm}$, respectively.

Figure 15 shows composition and distribution of integrated ET in Tianjin. It demonstrates that ET from irrigation lands is the dominant part that accounts for $53 \%$ of the total ET; the second highest ET was from ecology, with $23 \%$ from town ecology and $20 \%$ from other ecology. Accordingly, the sequence of the feasibility of ET control from easy to difficult is as follows: agriculture, ecology in town, industry, and residential use.

Judging by the results of analysis of ET from various types of land use and industries, the industries showing lower water use efficiency require some improvements. Control of the regional integrated ET can be attained, and regional authorities may finally implement the goals of water use efficiency and reap the resulting benefits. 


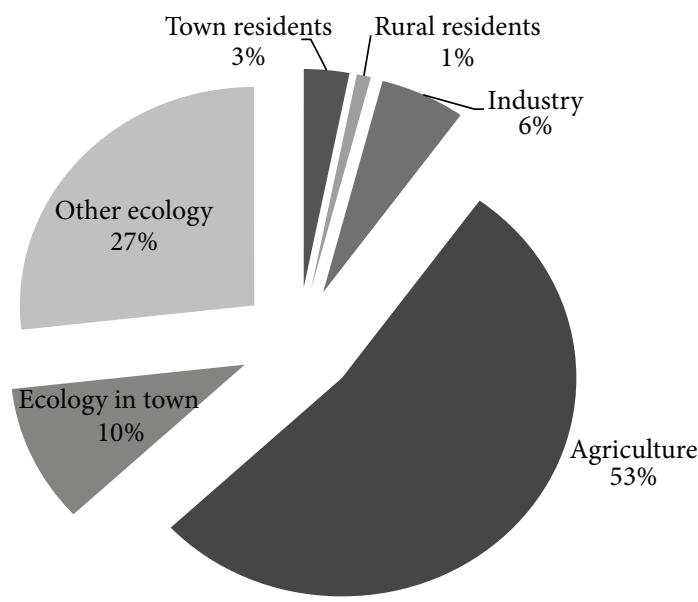

FIgURE 15: Analysis of integrated ET in Tianjin.

\section{Conclusions}

In this work, a regional WAS model was used to achieve ET control; the model was developed to implement integrated simulation of a natural and artificial water cycle. In the process of calibration and validation, a "piece-by-piece" approach was utilized to solve the model and to obtain rational and effective results from the model step by step. A case study was conducted to explore some of the capabilities of the model in the Tianjin basin.

Among the results of practical application of the model, we can see that the runoff dropped off gradually from 1980 to 2004, and synchronously, the regional total ET changed just like the runoff. This finding demonstrates that the regional total ET strongly correlates with precipitation and the water volume of inflow because the ET mainly comes from various uses of land. Distribution of regional ET also shows that ET of the croplands and other plant lands is higher than that of residential units and industry. The ET from RS estimates the ET of underlying surface features based on the retrieval principle and cannot reflect the regional total ET, such as the ET related to the volume consumed by residential units and industry, but it is used as a tool for evaluating and analyzing the scenario for water resource planning and management. This is because the ET from residential units and industry represents a very small fraction in most regions.

\section{Conflict of Interests}

The authors declare that there is no conflict of interests regarding the publication of this paper.

\section{Acknowledgments}

This study was funded by the MWR Project "The Theory and Practice of Construction of a Water-Saving Society in China" ([2006]50), a Project of Natural Sciences for Youth Foundation of China (51009149), and IWHR Project (ZJ1224).

\section{References}

[1] A. K. Biswas, "Integrated water resources management: a reassessment," Water International, vol. 29, no. 2, pp. 248-256, 2004.

[2] J. F. Booker and R. A. Young, "Modeling intrastate and interstate markets for colorado river water resources," Journal of Environmental Economics and Management, vol. 26, no. 1, pp. 66-87, 1994.

[3] A. Elshorbagy and L. Ormsbee, "Object-oriented modeling approach to surface water quality management," Environmental Modelling and Software, vol. 21, no. 5, pp. 689-698, 2006.

[4] A. Porporato and L. Ridolfi, "Nonlinear analysis of river flow time sequences," Water Resources Research, vol. 33, no. 6, pp. 1353-1367, 1997.

[5] R. S. Govindraju and A. R. Rao, Artificial Neural Networks in Hydrology, Kluwer Academic Publishers, Dordrecht, The Netherlands, 2000.

[6] E. Foufoula-Georgiou and P. K. Kitanidis, "Gradient dynamic programming for stochastic optimal control of multidimensional water resources systems," Water Resources Research, vol. 24, no. 8, pp. 1345-1359, 1988.

[7] R. M. Hirsch, "A comparison of four streamflow record extension techniques.," Water Resources Research, vol. 18, no. 4, pp. 1081-1088, 1982.

[8] S. L. Neitsch, J. G. Arnold, J. R. Kiniri, and J. R. Williams, Soil and Water Assessment Tool Theoretical Documentation Version 2000, Grassland, Soil and Water Research Laboratory and Blackland Research Center, Temple, Tex, USA, 2001.

[9] M. G. McDonald and A. W. Harbaugh, "A modular threedimensional finite-difference ground-water flow model," in U.S. Geological Survey Techniques of Water-Resources Investigations, Book 6, chapter A1, pp. 195-286, 1988.

[10] J. C. Refsgaard and B. Storm, "MIKE SHE," in Computer Models in Watershed Hydrology, V. J. Singh, Ed., pp. 809-846, Water Resource Publications, 1995.

[11] A. S. Donigian, B. R. Bicknell, and J. C. Imhoff, "Hydrological Simulation Program-Fortran (HSPF)," in Computer Models of Watershed Hydrology, V. P. Singh, Ed., pp. 395-442, Water Resources Publications, 1995.

[12] L. Brown, B. McDonald, J. Tysseling, and C. Dumars, "Water reallocation, market efficiency, and conflicting social values," in Water and Agriculture in the Western U.S.: Conservation, Reallocation, and Markets, G. D. Weatherford, Ed., Westview Press, Boulder, Colo, USA, 1982.

[13] M. Bray and D. Han, "Identification of support vector machines for runoff modelling," Journal of Hydroinformatics, vol. 6, pp. 265-280, 2004.

[14] G. Belaineh, R. C. Peralta, and T. C. Hughes, "Simulation/optimization modeling for water resources management," Journal of Water Resources Planning and Management, vol. 125, no. 3, pp. 154-161, 1999.

[15] X. Liang, D. P. Lettenmaier, E. F. Wood, and S. J. Burges, "A simple hydrologically based model of land surface water and energy fluxes for general circulation models," Journal of Geophysical Research, vol. 99, no. 7, pp. 14415-14428, 1994.

[16] Y. Huang, D. Jiang, D. Zhuang, Y. Zhu, and J. Fu, "An improved approach for modeling spatial distribution of water use profita case study in Tuhai Majia Basin, China," Ecological Indicators, vol. 36, pp. 94-99, 2014.

[17] J. Dong, D. Zhuang, X. Xu, and L. Ying, "Integrated evaluation of urban development suitability based on remote sensing and 
GIS techniques: A case study in Jingjinji area, China," Sensors, vol. 8, no. 9, pp. 5975-5986, 2008.

[18] X. Sang, Z. Zhou, H. Wang, D. Qin, Z. Zhai, and Q. Chen, "Development of soil and water assessment tool model on human water use and application in the area of high human activities, Tianjin, China," Journal of Irrigation and Drainage Engineering, vol. 136, no. 1, pp. 23-30, 2010.

[19] J. E. Nash and J. V. Sutcliffe, "River flow forecasting through conceptual models part I-a discussion of principles," Journal of Hydrology, vol. 10, no. 3, pp. 282-290, 1970. 

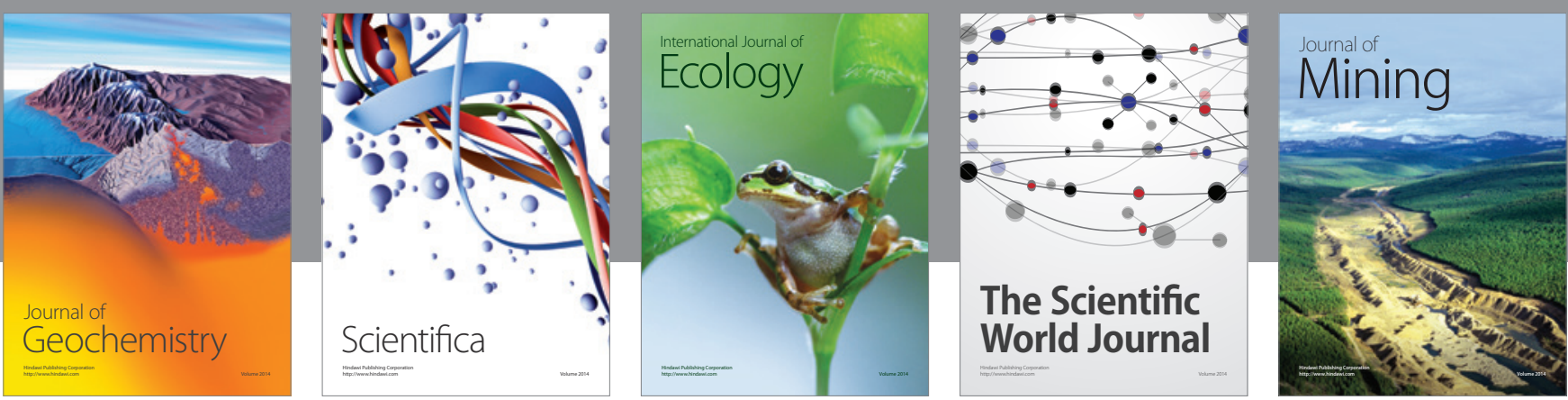

The Scientific World Journal
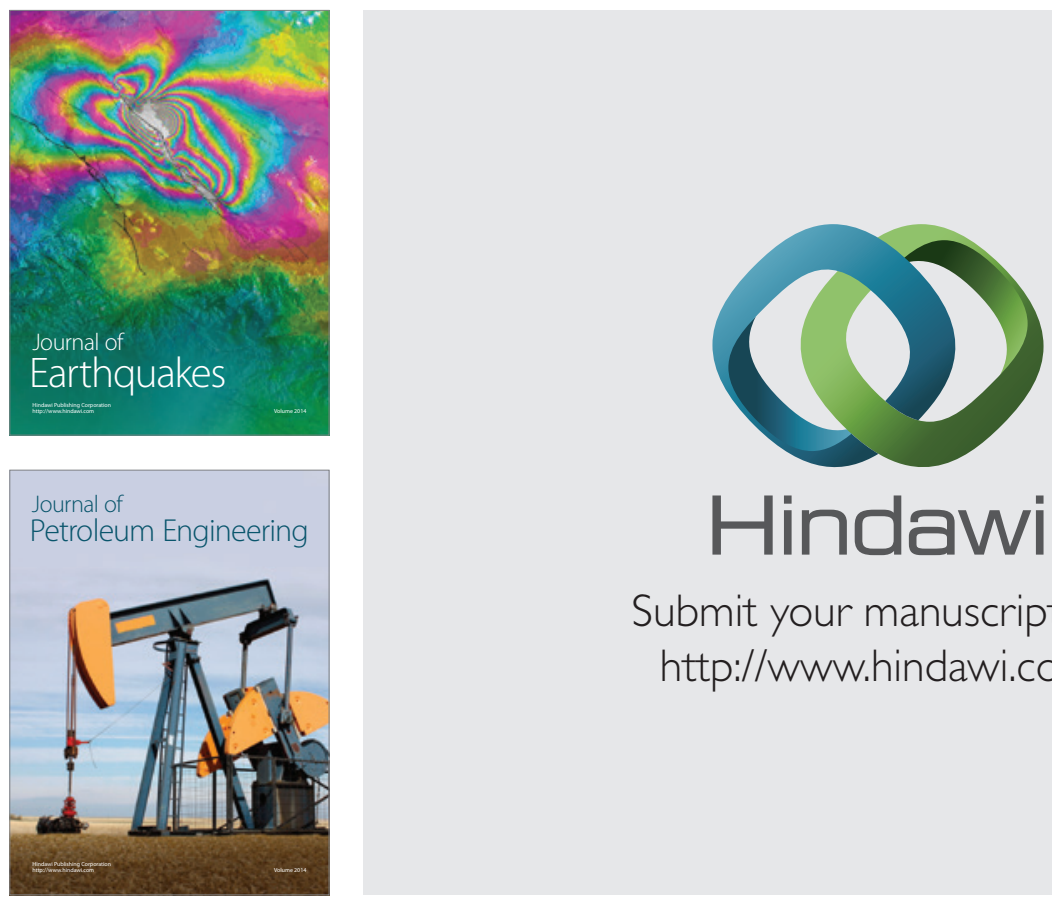

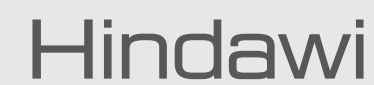

Submit your manuscripts at

http://www.hindawi.com
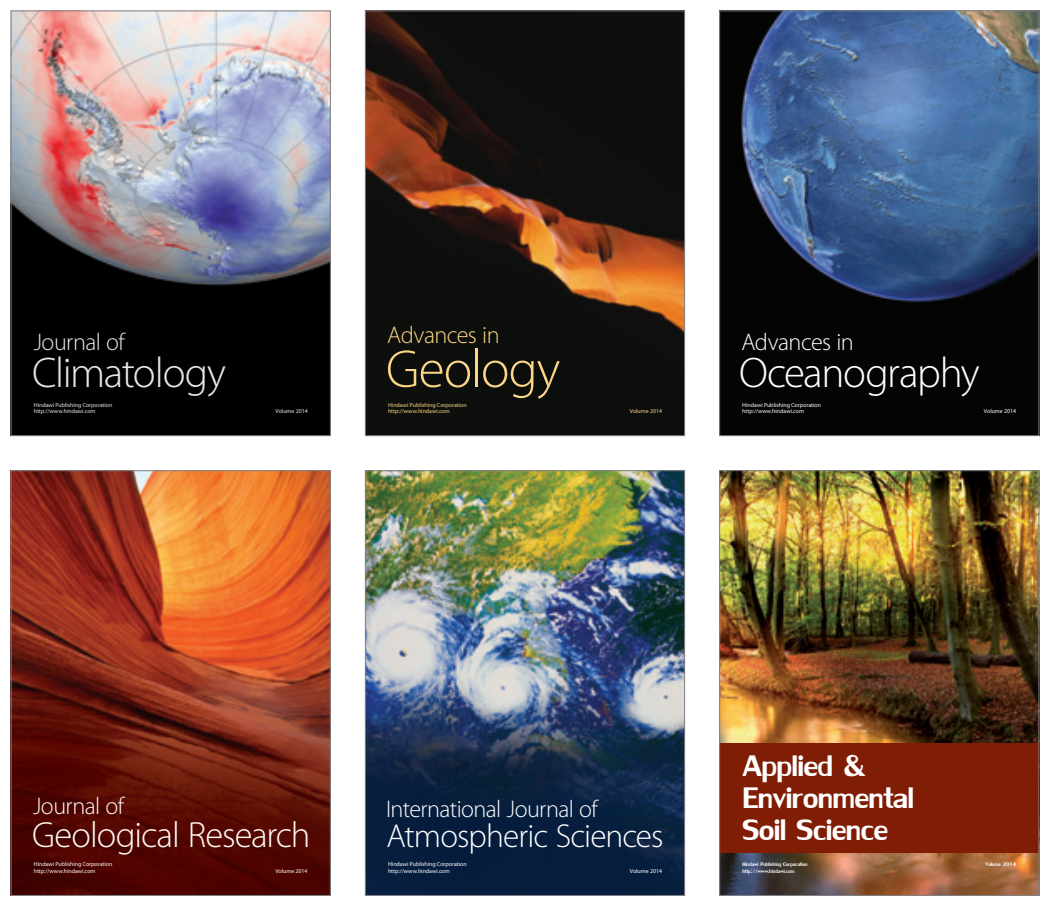
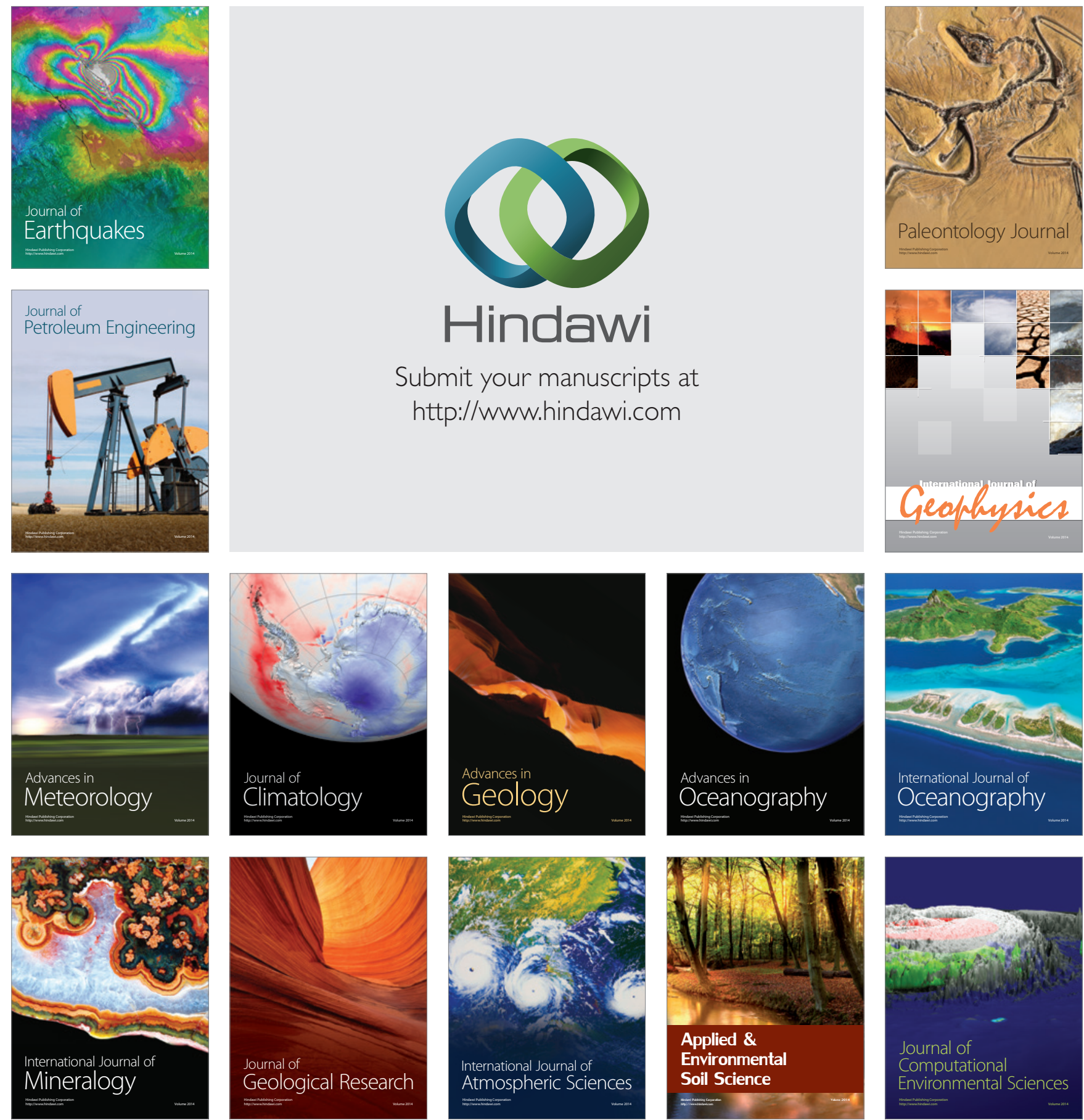